\title{
Developing an Industry 4.0 Readiness Model for Indian Engineering Industries
}

\author{
Michael Sony ${ }^{1} \&$ P. S. Aithal ${ }^{2}$ \\ ${ }^{1}$ Post-Doctoral Researcher, College of Engineering \& Technology, Srinivas University, Mangalore \\ 575 001, India \\ Email: emailofsony@gmail.com \\ ${ }^{2}$ ViceChancellor, Srinivas University, Mangalore, India, \\ E-Mail: psaithal@gmail.com
}

Area/Section: Industrial Engineering.

Type of the Paper: Conceptual Analysis.

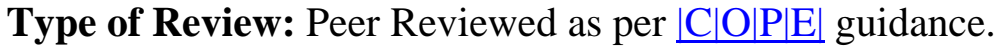

Indexed in: OpenAIRE.

DOI: http://doi.org/10.5281/zenodo.4008855.

Google Scholar Citation: IJMTS.

How to Cite this Paper:

Sony., Michael,\& Aithal, P. S. (2020). Developing an Industry 4.0 Readiness Model for Indian Engineering Industries. International Journal of Management, Technology, and Social Sciences (IJMTS), 5(2), 141-153. DOI: http://doi.org/10.5281/zenodo.4008855.

International Journal of Management, Technology, and Social Sciences (IJMTS) A Refereed International Journal of Srinivas University, India.

(C) With Authors.

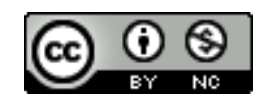

This work is licensed under a Creative Commons Attribution-Non-Commercial 4.0 International License subject to proper citation to the publication source of the work.

Disclaimer: The scholarly papers as reviewed and published by the Srinivas Publications (S.P.), India are the views and opinions of their respective authors and are not the views or opinions of the SP. The SP disclaims of any harm or loss caused due to the published content to any party. 


\title{
Developing an Industry 4.0 Readiness Model for Indian Engineering Industries
}

\author{
Michael Sony ${ }^{1} \&$ P. S. Aithal ${ }^{2}$ \\ ${ }^{1}$ Post-Doctoral Researcher, College of Engineering \& Technology, Srinivas University, Mangalore \\ 575 001, India \\ Email: emailofsony@gmail.com \\ ${ }^{2}$ ViceChancellor, Srinivas University, Mangalore, India, \\ E-Mail: psaithal@gmail.com
}

\begin{abstract}
For India to be a global economic superpower, the Indian Engineering Industry which at present is the largest foreign exchange earner must make its strong presence in the global markets. Industry 4.0 is one such initiative which has the power to transform the Indian Engineering Industry to be globally competitive along several strategic dimensions. Industry 4.0 is gradually making inroads and yet, there is no model to assess whether the Indian Engineering Industry is prepared to implement Industry 4.0. This study develops a multi-dimensional Industry4.0 readiness model by analysing in-depth the extant literature. A theoretical framework for assessment is developed. Further, the developed model is qualitatively analysed using the ABCD framework. Practical application of Industry 4.0 readiness model in Indian Engineering Industries is discussed. This is the first Industry 4.0 readiness model developed for Indian Engineering Industries.
\end{abstract}

Keywords:Industry 4.0, Readiness Model, Indian Engineering Industry, ABCD Framework, Industry 4.0 implementation.

\section{INTRODUCTION :}

Industry 4.0 has been receiving profound attention among the practitioners and academicians[1]. The organizations around the world have shown tremendous interest in Industry 4.0 which have the power to transform the organization into an integrated digital value creation process[2]. Industry 4.0 takes manufacturing to a new level by integrating cyber and physical systems within or across the organizations, using technologies such as AI, IoT, Cloud Manufacturing, CPS, Additive Manufacturing, etc which will enable organizations to enable customised and flexible manufacturing of products to meet customer needs[3].An organization can be digitally transformed using Industry 4.0 on both hardware and software dimensions. To cite an instance on hardware side three-dimensional simulation and printing involving "raw materials", "finished products", and "production cycle"[4]. On the software dimensions, "Software as a service (SaaS)" is another such feature which has opened total digitization of organizational functions.In terms of the definition of Industry 4.0, there is a shortage of a universal definition of Industry 4.0. One of the most prominent definition of Industry 4.0 in a strategic sense would be by Piccarozzi, Aquilani, and Gatti[5] they define "Industry 4.0 refers to the integration of Internet of Things technologies into industrial value creation enabling manufacturers to harness entirely digitized, connected, smart, and decentralized value chains able to deliver greater flexibility and robustness to firm competitiveness and enable them to build flexible and adaptable business structures, [acquiring] the permanent ability for internal evolutionary developments in order to cope with a changing business environment as the result of a purposely formulated strategy implemented over time" [6, 7]. The main motivation for organizations to carry out the application of Industry 4.0 is based to (a) Technological application push and (b) Technological application pull [8]. The technological application push is driven by advances in ICT, increased automation of 
manufacturing, digitalization of the organization, IoT, CPS, etc. In terms of technological application pull there is a need in the market, for the reduction of product development times, increased personalization, flexible manufacturing, faster decision making through decentralisation, etc[4]. Despite of organizationsimmense need to implement Industry 4.0, a large number of Industries are not entirely clear, about the "effect and impact" of Industry 4.0[9]. One of the reasons for unclarity could be because there is a lack of clarity as regards to what is Industry 4.0. A study recommends"12 design principles" and "14 technology trends” as a central tenant of Industry[10]. In another study, it is proposed 64 technologies which constitute Industry 4.0[11]. Thus, there is a lot of unclearness about what constitutes Industry 4.0. Another reason that Industry 4.0 is not immensely adopted by many Industries could be the high initial cost and lack of interoperability between IT systems[3, 12].In India, Industry 4.0 has received tremendous response from the Government and Industries. The "United Nations Industrial Development Organization (UNIDO)" posits that among the 10 global front runners in Industry 4.0, India is the only middle-income country which is rapidly transforming its production units using Advanced Digital Production( ADP)[13]. The "SAMARTH Udyog Bharat 4.0" an initiative from the "Government of India" is a strategic initiative in this regard. This programme by the Government of India is to help Industries to use to the advanced technologies of Industry 4.0 to make products and services which can be sold in the global markets[14].The application of Industry 4.0 in the "Indian engineering sector" will yield better results, as it has seen incredible growth in exports over recent years. To be a global superpower "Government of India” has appointed "Engineering export promotion council (EEPC)". The Indian Engineering Industries represent the biggest segment in the Indian Industry. It is also India's largest foreign exchange earner, as it contributes to $25 \%$ to Indian total exports in goods. It further has $30 \%$ weight in India's "Index of Industrial Production”[15]. The engineering industries being labour \& capital-intensive, the application of Industry 4.0 will lead to "competitive advantage" in both internal and external markets. Before, application of Industry 4.0, Indian Engineering Industries mustassess whether they are ready to implement Industry 4.0. In a generic perspective, Industry 4.0 readiness could be described as how an organization is poised to utilise the Industry 4.0 technologies to its benefits[4]. In other words, the organization can utilise the Industry 4.0 technologies to meet their goals and objectives. The ability of the organization will also depend on the context and as well as in the region where it is located. In a contextual sense, the challenges an organization faces in heavy engineering segment will be different from the textile industry. Similarly, the challenges in India would be different than challenges in Europe because of socio-technological factors. Some of the challenges faced by Indian Engineering Industries are the internet connectivity in India is a challenge, especially in rural areas. If the organization is located in rural areas of India, the large amount of data which needs to be transmitted over industrial ethernet. A large amount of data transmission would be a challenge to Industry 4.0 implementation. In 2019, India was ranked 79th in the network readiness index(NRI, 2019). The huge initial investment is a challenge for Indian Engineering Industries. This is especially difficult when the exports of engineeringgoods from India dropped by 6.2\% in the year 2019-20. Besides, the performance in March 2020, has been dismal due to Covid-19 pandemic (EEPC, 2020). During these challenging times finding the initial investment for implementing Industry 4.0 would be a challenge. The application of Industry 4.0 will warrant taking into confidence the trade unions as the existing workforce may feel threatened by automation suggested in Industry 4.0. Organizations must strategically deal with the trade union to convince them of its socio-technical benefits. Cybersecurity is another aspect organization fear because Industry 4.0 implementation will put sensitive information about the organization's products and services online. Miscreants can hack the information to create an undue advantage for some firms or create the loss to host firm. The skill requirement in Industry 4.0 is more polarised towards ICT and traditional engineering disciplines will have to orient core engineering skills towards ICT [45]. Considering these challenges for the implementation of Industry 4.0, thereis pertinent need to examine the Industry 4.0 readiness factor in Indian Engineering Industries. Thus, we ask the research question?

What are the dimensions of the Industry 4.0 readiness Model in Indian Engineering Industries? 
In the following section, we review the related works, objectives, conceptual analysis of dimensions, discussion, implications, and conclusion.

\section{RELATED LITERATURE :}

This section reviews the background literature on three themes (a) Industry 4.0, (b) Industry 4.0 Readiness models, and (c) Indian Engineering Industries.

\subsection{Industry 4.0}

The "German federal Government" launched Industry 4.0 as an initiative that aims to improve the competitiveness of the "German manufacturing Industries" in the year 2011[16]. Industry 4.0 revolves around the use of CPS in manufacturing, logistics, and other organizational functions using IoT and other technologies to develop products and services to meet customer needs. In a business sense, it will have a far-reaching impact on work organization in Industries, design of downstream services and value creation processes [17]. The conceptual and theoretical understanding of Industry 4.0 is ever-expanding. The 9 technologies pivotal for the application of Industry 4.0 are "Additive Manufacturing” , "Augmented reality”, “Autonomous Robots”, "Big data\& analytics”, “Cloud Computing”, “Cybersecurity”, "Horizontal and vertical system Integration”, IoT and "simulation”[18]. Another three technologies Real-time location systems \& Radio frequency identification systems, Mobile Technologies and Artificial intelligence is added to it[19, 20]. These technologies contribute to the design of "Cyber - Physical Systems" (CPS) in Industry 4.0. It is defined as "transformative technologies for managing an interconnected system between physical assets and computational technologies"[21]. The 5C architecture for CPS is"connection", "conversion", "cyber", "cognition" and "configuration". The connection layer deals with acquiring precise and reliable data from machines through "sensors" or "controllers" or "enterprise manufacturing systems". Conversion layer calls for converting data to information, through algorithms using prognostics and health management applications. This is layer is responsible for adding "self-awareness" to machines. The third layer is the cyber level that serves as a "central information hub" of all machines. Specific analytics are used in the cyber layer to extract information to provide insights as regards to the status of machines. Cognition layer calls for a thorough knowledge of the monitored system. It is a component which deals with proper presentation of information to the experts or employees. Configuration layer acts as a feedback element from the cyber level to the physical level. It acts as a supervisory component which will help the machines to self-configure and be self-adaptive. Three more extension to the 5C architecture are suggested [22]. The three extended layers are "coalition”, "customer" and“content”. The coalition element is focussed on "value chain integration" and "production chain integration" among various organizations involved in the value creation process. The customer layer focusses on the customer play in the "design process", "production process" and "after sales service" of the product. The content layer is devoted to "extracting", "storing", and "inquiring the product traceability record". The individual product information is stored in it from the manufacturing stage to the operation stage. Thus, Industry 4.0 is total automation of all organizations functions.

\subsection{Industry 4.0 readiness Models}

Industry 4.0 readiness is used to describe how ready an Industry is to exploit the Industry 4.0 to obtainadvantages from it, to meet the objectives of the organization. A similar concept is a maturity model. The difference between maturity and readiness is that readiness is before the application of Industry 4.0 and maturity is gauged after the implementation of Industry[23]. Previous researchers have studied Industry 4.0 readiness models [4, 24]. However, the vast majority of the Industry 4.0 readiness models are less "pragmatic" in terms of the rapidly advancing objectives of the organizations[4]. Industry 4.0 readiness models are important for the organizations as it will help in understanding the present position of the organization and the change that is required for the application of Industry 4.0. In the Industry 4.0 implementation sense, it can be seen as a management tool, which will help in realignment, reconfiguration and renewal of organizations capabilities and capacities[25].Furthermore, the application of Industry 4.0 will result ina creation of new business models, strategies, KPI, etc [4, 6]. Thus, it is pertinent to 
understand the dimensions of Industry 4.0 as regards to its dimensionality and contextual significance.

\subsection{Indian Engineering Industries}

The Indian Engineering Industry is the largest segment among Indian Industries, and it accounts for $27 \%$ of total factories in the Industrial sector. It contributes to $63 \%$ of all foreign collaborations and is the largest exporter. It is broadly categorised into the heavy and light engineering sector, with heavy engineering contributing to $80 \%$. Engineering Export promotion council is the premier government body which oversees the Engineering sector. In the last decade, it is seen that India's stake in the"global engineering trade” is around $1.2 \%$ compared to China's $12 \%$. Besides India does not possess any “dominant position” in any of the 34-product category defined by DGCIS classification and is termed as "follower" nation. India is trying to achieve dominant position, in some product categories in the next five years. In the overall Engineering export basket, only 6\% is constituted "high tech goods", others were "low and medium technology goods". The reduction in high tech industries is due to the fact all exporters relied on labour cost arbitrage[15]. However, this is not sustainable in the long run, as emerging concepts around the world like"near shoring" and "disruptive technologies" will break the advantage in the long run. Besides, the bulk of exports comes from SMEs. They do not have enough financial powers or has access to pathbreaking research or technology. The global markets are becoming extremely competitive and products are becoming smart. Some of the challenges experienced by Indian Engineering Industries were lack of "adequate physical infrastructure, high energy costs, high interest rates, lack of best practices, increase the cost of manufacturing, outdated manufacturing processes and un-refunded tax benefits" [26].Therefore, it is imperative that to be a sustainable exporter in the global markets the Indian Engineering Industries needs to be globally competitive and Industry 4.0 will be a great initiative to meet the objectives.

\section{DIMENSION OF INDUSTRY 4.0 READINESS MODEL :}

The Industry 4.0 readiness model for Indian Engineering Industry will consists of the dimensions as(a) organizational strategy readiness of Indian engineering industry for Industry 4.0,(b) digitization Level of Indian engineering industries,(c) digitization level of the supply chain of Indian engineering industries,(d) Level of smart products in Indian engineering industries,(e) "Employee adaptability" with Industry 4.0 skills in Indian Engineering Industries and (f) Top management support \& leadership in Indian Engineering Industry for Industry 4.0.

\subsection{Organizational Strategy Readiness of Indian Engineering Industry for Industry 4.0}

Industry 4.0 implementation is a major decision and it encompasses whole aspects of the business from customers, suppliers, organization, environment and even society[24, 27]. Industry 4.0 changes long term relationships between (a) "organization and Nature”,(b) “organization and local communities",(c) "organization and value chains”,(d) "organization and humans". The relationship between organization and nature changes because Industry 4.0 entails better resource efficiency as resources usage is monitored digitally. Besides, manufacturing processes are sustainable due to the implementation of Industry 4.0[28]. The second relationship that gets changed is between the organization and local communities. Industry 4.0 due to digitalisation increases the customer base and hence geographical proximity is reduced[29]. Besides, there is an integration of customers and other stakeholders in the design \& manufacturing of products and services[30]. The third relationship that is impacted is between the organization and value chains. There is distributed manufacturing and ever responsive value chains with smart logistics[31]. This facet will help to personalise products and services. The fourth relationship which gets changed is between organization and humans. Industry 4.0 entails improved work conditions, ergonomically challenging tasks will be carried out by robots \&cobots, human-oriented interfaces [32]. Thus, an organization strategy while implementing Industry 4.0 should consider all four aspects. A neglect in any of the dimensions in strategic implementation will result in Industry 4.0 in Indian Engineering Industry isnot being successful.

\subsection{Digitization Level of Indian Engineering Industries}

The "level of digitization" of organization means the number of assets of organization which are fitted with sensors or digital means of sensing the state of assets and communicate with the cyber systems of the 
organization [30]. This can also be understood in terms ofthe level of digitization used in managing the organization i.e. planning, organizing, leading, controlling and coordinating. The implementation of smart manufacturing depicts highly automated production systems with smart materials possessing manufacturing instruction, in them and moving in an autonomous manner with the minimal human intervention[33, 34]. Total application of Industry 4.0 also enables "autonomous decision making” in terms of day to day operational decisions are automated in organizations [35, 36].Higher the "level of digitization" of the Indian Engineering organization, it would be ready for the application of Industry 4.0.

\subsection{Digitization Level of the Supply Chain of Indian Engineering Industries}

"Supply chain" is perennial for the success of an organization in terms of its achieving organizational goals such as reducing cost and increasing organizational profits[37]. The success of supply chain operations depends on how well the systems, processes, and structures with the supply chain for planning, organising, coordinating, controlling, and leading to achieving the supply chain goals. In Industry 4.0, for the success of the supply chain these constituent elements in the supply chain are digitalised[30]. This results in a business ecosystem wherein the participating organizations work the make joint optimisation to create successful delivery of products to the customers. The digitization of the supply chain further results in "big data” being generated within the supply chain systems, structures, and processes[38]. These big data are strategically used by the organization to manage the supply chain. Besides, it further helps to extend the services along with product delivery to create unique models for product customisation. In smart factories supply chain operates in a dynamic manner, self-regulating and self-configuring manner to achieve the goals customisation of products for customers[31]. The production 4.0 and logistics 4.0 are digitally integrated to create a unique model which can be used in a strategically to achieve organizational goals[39].Some of the challenge faced by supply chain due to digitalization are (1) The big data generated within the supply chain are stored in the cloud with all members having access to it with certain access privileges. This can misuse by organizations to achieve their individual goals. (2) Sometimes these big data are trusted to a third vendor for cloud storage. This creates security issues, as rivals will always be in the hunt for such big data. For example, data on customer order quantity, customer details, price, discounts, delivery dates etc can be used by the rivals to erode the competitive advantage of the parent firm[40, 41]. If the supply chain is made digitally secure it will result in immense "competitive advantage" for all the participating organization. The success of Industry 4.0 in Indian Engineering Industries will depend on the extent to which the supply chain of the organization is digitalised.

\subsection{Level of Smart Products in Indian Engineering Industries}

Smart product is defined as "interact and communicate with themselves and each other-and with humanson an ongoing basis by sending and receiving data through the Internet that is stored and organised in a database"[42]. Smart products can be defined as "Smart objects are regarded as a physical embodiment with communication functionality, possessing a unique identifier, some basic computing capabilities and a way to detect physical phenomena and to activate action shaving an effect on physical reality”[43]. Smart products have therefore three features,(1) Environmental data of is collected products through "sensors",(2) It can be controlled from remote or other entities through an "actuators" and 3) The products are connected through "Network connectivity" using technologies such as WiFi, Blue tooth, RFID, etc[44]. The three main characteristics exhibited by Smart products are "connectivity, intelligence and ubiquity". Connectivity stands for exchange of information with objects, servers, other devices etc. Intelligence calls for products being able to take self-regulated action based on intelligence algorithms using previous data. Ubiquity means these products can be used from anywhere, anytime and from any platform [44]. The success of Industry 4.0 in Indian Engineering Industries isdependenton the degree to which the organizations products are smart in both heavy and light engineering industries.

\section{5 "Employee adaptability” with Industry 4.0 skills in Indian Engineering Industries}

The traditional work skills warranted by the organization will transformwith the application of Industry 4.0[38]. Thus, existing employees within the organization must unlearn old methods and learn new skills to carry out the jobs[45]. The new-age skill requirement in most professions in the era of Industry 4.0 will be 
polarised towards ICT[1]. The hard skill requirements in Industry 4.0 are application trouble shooting \& maintenance, software installation \& trouble shooting, automation, data security, \& data connectivity[24, 46]. Besides, there would be a requirement of other soft skills such as "creativity", "problem solving", teamwork, "critical thinking”, "out of the box thinking”, etc[47]. Industry 4.0 application is a "radical change initiative"[48]. The organization structures, processes, systems, procedures, decision making, etc is transformed with the application of Industry 4.0. The employees working in one department will have to be accommodated in other departments, due to the implementation of Industry 4.0. This may be because the existing jobs will be done by the machines. How well the employees change with the new requirement of Industry 4.0 requirement will determine the adaptability of the employees. Therefore, for the success of Industry 4.0 implementation in Indian Engineering Industries, will depend on "how the employeeswill adapt with the new skill requirement of Industry 4.0".

\subsection{Top Management Support \& Leadership in Indian Engineering Industry for Industry 4.0}

Industry 4.0 warrants physical resources in terms of IoT, CPS, Additive manufacturing, etc[49]. Similarly, there is a need for software resources such as machine learning algorithms, ERP software's, etc[50]. Besides, there is a need for highly skilled consultants and employees to make the joint optimisation of human and technical systems a success[51]. The acquiring and maintaining of these resources require financial obligations and consequently, the top management support will ensure an informed organizational strategy-basedsupport for Industry 4.0 initiatives. The top management knowledge[52] about Industry 4.0 is also a pertinent factor to consider in Industry 4.0 implementation. The top management knowing about Industry 4.0, will have a realistic expectation from its implementation. Industry 4.0 should not be a magical cure for everything, rather as a means for achieving organizational goals. The informed top management will not exert an unrealistic pressure on Industry 4.0 implementation team[38]. A strong leader will help in smooth execution of Industry 4.0[53]. The leadership skills required for Industry 4.0 is mixture of leadership styles[54]. A strong leader will help the organization to undergo a smooth transition towards Industry 4.0. In order to assess the readiness of Industry 4.0 in Indian Engineering Industries, the top management support have to measure in terms of top management knowledge about Industry 4.0, resourcing allocation support exhibited by the top management towards Industry 4.0 and also leadership kills in top management towards Industry 4.0.

\section{THEORETICAL FRAMEWORK :}

The Industry 4.0 readiness model for Indian Engineering Industries will constitute of thesix dimensions as depicted in Figure 1. Therefore, in this study we define Industry 4.0 readiness model for Indian Engineering Industry as the model which will help to assess, how ready an organization is in terms of organizational strategy readiness of Indian engineering industry for Industry 4.0, digitization Level of Indian engineering industries, digitization level of the supply chain of Indian engineering industries, Level of smart products in Indian engineering industries, "Employee adaptability" with Industry 4.0 skills in Indian Engineering Industries and Top management support \& leadership in Indian Engineering Industry for Industry 4.0 in order to derive maximum benefits of Industry 4.0 to meet the organizational goals and objectives. The construct of Industry 4.0 readiness model is a multi-dimensional construct which is composed of six dimensions. These factors will be interrelated to each other as these are dimensions of the same construct, however, each of the dimension will have its distinctness too because it measures a unique phenomenon.

\section{QUALITATIVE ANALYSIS OF INDUSTRY 4.0 READINESS MODEL THROUGH ABCD} FRAMEWORK :

The proposed Industry 4.0 readiness model is qualitatively evaluated using the ABCD framework developed by Aithal et al.(2015) [55-59].

\subsection{Advantages}

1. Industry 4.0 readiness model will help Indian engineering industries to address potential pitfalls while implementing Industry 4.0 
2. Self-assessment tool which can be easily used by the Indian Engineering Industries

3. It will help to analyse the Indian Engineering Industry in the six dimensions and comparatively analyses the SWOT in each dimension

4. A generic six- dimensional tool which can be used in both heavy and light engineering industries

5. Assess the resource capability of the organization with respect to implementation of Industry 4.0
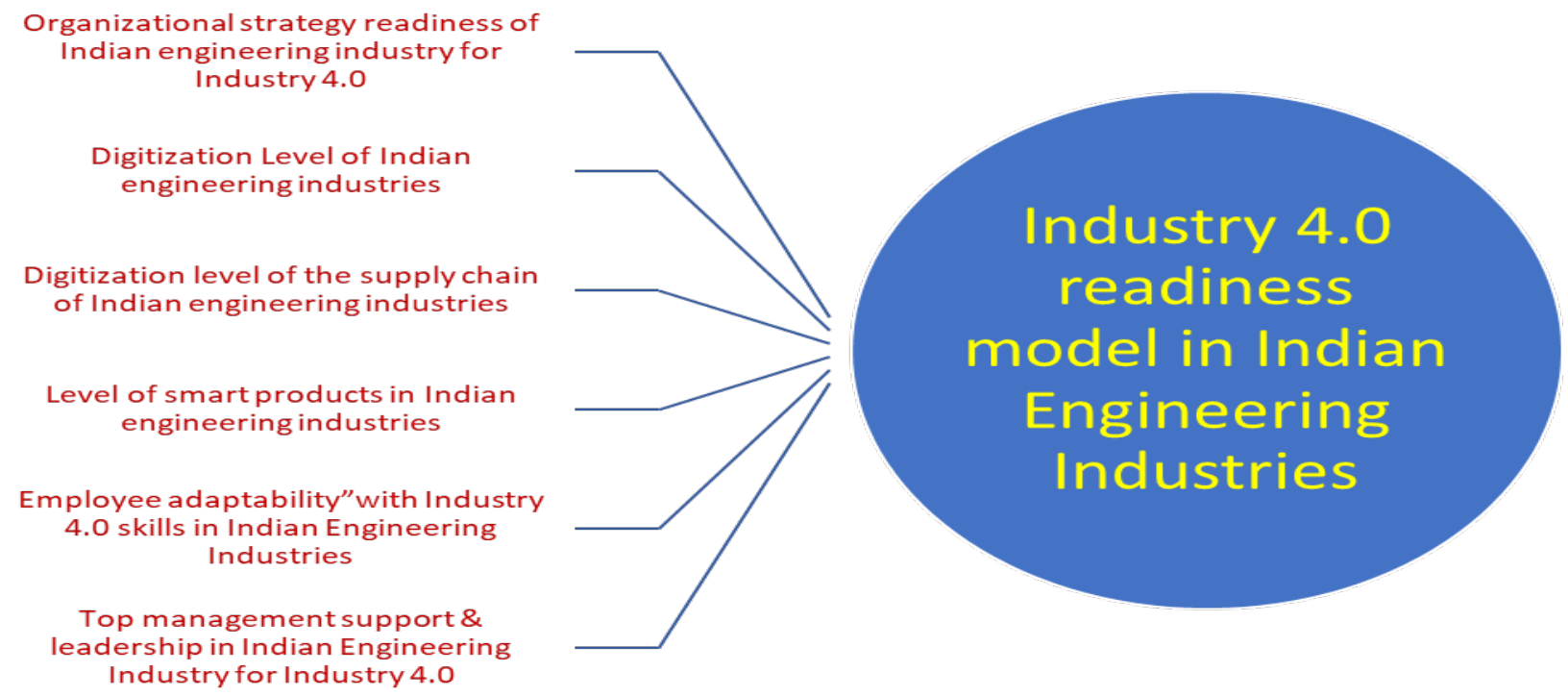

Fig 1: Theoretical Model of dimensions of Industry 4.0

\subsection{Benefits}

1. Readiness model will help organizations to choose the best resource allocation in each of the dimensions of Industry 4.0 model.

2. A simple model which can be easily understood by both top management and middle-level managers

3. Could be used as a risk analysis framework while implementing Industry 4.0

4. It might be used to manage employee skills for Industry 4.0

5. Help to understand the present state of the organization and how the future state could be attained to implement Industry 4.0

\subsection{Challenges}

1. An objective assessment should be carried out in all the proposed dimensions to arrive at the present state.

2. 360-degree assessment should be carried out by taking into all stakeholder'sviewpoint while assessing the dimensions.

3. Consensus on the readiness of each of the dimension could be a challenge. To cite an example,the employee may feel that management is not supportive and top management may feel they are very supportive and accommodative. Therefore, the consensual discussion should be carried out on each of the dimensions.

4. The weighting may be assigned to the different dimensions of the readiness model. The weighting of the assigned model will have to be carefully selected based on the sector of Indian Engineering Industry where it would be applied. 


\subsection{Disadvantage}

1. Self-assessment of Industry 4.0 readiness scale might result in inflated scores at times because of socially desirable responding. Therefore, the anonymity of responders should be ensured.

2. The results of self-assessment of Industry 4.0 readiness would be influenced personal knowledge of the respondents. However, this impact could be avoided by averaging the scores of multiple respondents.

3. The respondents while using the Industry 4.0 readiness model should retrospectively analyse the organizations present state on the proposed dimensions, therefore, analyses would be subjected to memory decay

\section{IMPLICATIONS FOR THE INDIAN ENGINEERING INDUSTRIES :}

The Industry 4.0 readiness model can be used by the Indian Engineering Industries to assess the readiness to implement Industry 4.0. This model should be used before the implementation of Industry 4.0. The assessment of each of the proposed dimension should be carried out by the Industry 4.0 implementation committee. Items specific with respect to the dimension should be generated for the analyses. Contextualisation of items with respect to the Industry where it is applied should also be carried out. To bring in the objectivity for the analysis, the items should be rated by multiple stake holders. This will help to remove the subjectivity bias. A score for each dimension should be arrived at and the percentage score should be calculated for each dimension. It will help to understand how effectively each of the dimensions is implemented in the organizations. If the percentage score for each dimension is less than $50 \%$, before the implementation of Industry 4.0 that dimension should be improved. To cite an instance if the top management support and leadership score is less than 50\%. Efforts should be made to improve it in terms of initiating programs for top management to understand what Industry 4.0 is. Also, the top management should be made to understand the roles and responsibilities which they will discharge for the success of Industry 4.0. Only when all the dimensions score is above 75\%, the Indian Engineering Industries should venture out to implement Industry 4.0. This practical Industry 4.0 readiness model will help the organizations to objectively predict how successful the organization would be while implementing Industry $4.0[60-61]$.

\section{CONCLUSIONS :}

Indian Engineering Industries is one of the biggest segments in the Indian Industries and application of Industry 4.0 will transform them to be competitive in the global markets. Industry 4.0 is gradually making inroads in the Indian Engineering Industries. Before, an organization ventures out to implement they need to carry out a certain assessment to understand how successful the implementation will be in the organization. This study proposes a framework to carry out the Industry 4.0 assessment called Industry 4.0 readiness model. The framework is a multi-dimensional and will help the organizations to predict how successful Industry 4.0 will be in their organization. This study used a theoretical framework designed by the extant literature. Future study should venture out to confirm the dimensionality with qualitative and quantitative research to develop a scale. Besides, future studies should also statistically explore the dimensionality of the scale.

\section{REFERENCES :}

[1] Sony, M., \& Naik, S. (2020). Critical factors for the successful implementation of Industry 4.0: a review and future research direction. Production Planning \& Control, 31(10), 799-815.

[2] Brkic, V. K. S., Veljkovic, Z. A., \& Petrovic, A. (2019). Industry 4.0 Technology and Employees Behavior Interaction in Serbian Industrial Companies. In International Conference on Applied Human Factors and Ergonomics (pp. 94-103). Springer.

[3] Xu, L. Da, Xu, E. L., \& Li, L. (2018). Industry 4.0: state of the art and future trends. International Journal of Production Research, 56(8), 2941-2962. 
[4] Stentoft, J., Adsbøll Wickstrøm, K., Philipsen, K., \& Haug, A. (2020). Drivers and barriers for Industry 4.0 readiness and practice: empirical evidence from small and medium-sized manufacturers. Production Planning \& Control, 1-18.

[5] Piccarozzi, M., Aquilani, B., \& Gatti, C. (2018). Industry 4.0 in Management Studies: A Systematic Literature Review. Sustainability, 10(10), 3821.

[6] Prause, G. (2015). Sustainable business models and structures for Industry 4.0. Journal of Security \&Sustainability Issues, 5(2), 159-169.

[7] Koether, R. (2018). Taschenbuch der Logistik. Carl Hanser Verlag GmbH Co KG.

[8] Lasi, H., Fettke, P., Kemper, H.-G., Feld, T., \& Hoffmann, M. (2014). Industry 4.0. Business \& Information Systems Engineering, 6(4), 239-242.

[9] Bibby, L., \& Dehe, B. (2018). Defining and assessing industry 4.0 maturity levels-case of the defence sector. Production Planning \& Control, 29(12), 1030-1043.

[10] Ghobakhloo, M. (2018). The future of manufacturing industry: a strategic roadmap toward Industry 4.0. Journal of Manufacturing Technology Management, 29(6), 910-936.

[11] Klingenberg, C. O., Borges, M. A. V., \& Antunes Jr, J. A. V. (2019). Industry 4.0 as a data-driven paradigm: a systematic literature review on technologies. Journal of Manufacturing Technology Management.

[12] Fatorachian, H., \& Kazemi, H. (2018). A critical investigation of Industry 4.0 in manufacturing: theoretical operationalisation framework. Production Planning \& Control, 1-12.

[13] UNIDO. (2020). Industrial Development Report 2020. Industrializing in the digital age. Retrieved from https://www.unido.org/resources-publications-flagship-publications-industrial-development-reportseries/idr2020

[14] SAMARTH Udyog Bharat 4.0. (2019). Industry 4.0: SAMARTH Udyog Bharat 4.0. Retrieved from https://www.samarthudyog-i40.in/about-i40\#

[15] EEPC. (2020). Indian Engineering Electrifying Growth. Retrieved from http://www.eepcindia.org/download/IndianEngineeringBrochure-200819124444.pdf

[16] Hermann, M., Pentek, T., \& Otto, B. (2016). Design principles for industrie 4.0 scenarios. In System Sciences (HICSS), 2016 49th Hawaii International Conference on (pp. 3928-3937). IEEE.

[17] Kagermann, H., Helbig, J., Hellinger, A., \& Wahlster, W. (2013). Recommendations for implementing the strategic initiative INDUSTRIE 4.0: Securing the future of German manufacturing industry; final report of the Industrie 4.0 Working Group. Forschungsunion.

[18] Rubmann, M., Lorenz, M., Gerbert, P., Waldner, M., Justus, J., Engel, P., \& Harnisch, M. (2015). Industry 4.0: The future of productivity and growth in manufacturing industries. Boston Consulting Group, 9.

[19] Salkin, C., Oner, M., Ustundag, A., \& Cevikcan, E. (2018). A conceptual framework for Industry 4.0. In Industry 4.0: Managing The Digital Transformation (pp. 3-23). Springer.

[20] Saucedo-Martínez, J. A., Pérez-Lara, M., Marmolejo-Saucedo, J. A., Salais-Fierro, T. E., \& Vasant, P. (2018). Industry 4.0 framework for management and operations: a review. Journal of Ambient Intelligence and Humanized Computing, 1-13.

[21] Bagheri, B., Yang, S., Kao, H.-A., \& Lee, J. (2015). Cyber-physical systems architecture for selfaware machines in industry 4.0 environment. IFAC-PapersOnLine, 48(3), 1622-1627. 
[22] Jiang, J.-R. (2018). An improved cyber-physical systems architecture for Industry 4.0 smart factories. Advances in Mechanical Engineering, 10(6), 1-15.

[23] Erol, S., Schumacher, A., \& Sihn, W. (2016). Strategic guidance towards Industry 4.0-a three-stage process model. In International conference on competitive manufacturing (Vol. 9, pp. 495-501).

[24] Sony, M., \& Naik, S. (2019). Key ingredients for evaluating Industry 4.0 readiness for organizations: a literature review. Benchmarking: An International Journal, 27(7), 2213-2232. https://doi.org/https://doi.org/10.1108/ BIJ-09-2018-0284

[25] Felch, V., Asdecker, B., \& Sucky, E. (2019). Maturity models in the age of Industry 4.0-Do the available models correspond to the needs of business practice?

[26] EEPC. (2019). Strategy Paper for the Growth of Indian Engineering Exports (2014-19). Retrieved from https://www.eepcindia.org/download/150323172336.pdf

[27] Brettel, M., Friederichsen, N., Keller, M., \& Rosenberg, M. (2014). How virtualization, decentralization and network building change the manufacturing landscape: An Industry 4.0 Perspective. International Journal of Mechanical, Industrial Science and Engineering, 8(1), 37-44.

[28] Kamble, S. S., Gunasekaran, A., \& Gawankar, S. A. (2018). Sustainable Industry 4.0 framework: A systematic literature review identifying the current trends and future perspectives. Process Safety and Environmental Protection, 117, 408-425.

[29] Santos, C., Mehrsai, A., Barros, A. C., Araújo, M., \& Ares, E. (2017). Towards Industry 4.0: an overview of European strategic roadmaps. Procedia Manufacturing, 13, 972-979.

[30] Lichtblau, K., Stich, V., Bertenrath, R., Blum, M., Bleider, M., Millack, A., ... Schroter, M. (2015). Industrie 4.0-Readiness. Impuls-Stiftung des VDMA Aachen-Köln, 52(1), 1-77.

[31] Majeed, A. A., \& Rupasinghe, T. D. (2017). Internet of things (IoT) embedded future supply chains for industry 4.0: An assessment from an ERP-based fashion apparel and footwear industry. International Journal of Supply Chain Management, 6(1), 25-40.

[32] Peruzzini, M., Grandi, F., \& Pellicciari, M. (2018). Exploring the potential of Operator 4.0 interface and monitoring. Computers \& Industrial Engineering, 139(1), 105600.

[33] Bassi, L. (2017). Industry 4.0: Hope, hype or revolution? In 2017 IEEE 3rd International Forum on Research and Technologies for Society and Industry (RTSI) (pp. 1-6). IEEE.

[34] Weyer, S., Schmitt, M., Ohmer, M., \& Gorecky, D. (2015). Towards Industry 4.0-Standardization as the crucial challenge for highly modular, multi-vendor production systems. Ifac-Papersonline, 48(3), 579-584.

[35] Zanero, S. (2017). Cyber-physical systems. Computer, 50(4), 14-16.

[36] Baheti, R., \& Gill, H. (2011). Cyber-physical systems. The impact of control technology, 12(1), 161-166.

[37] Korpela, K., Hallikas, J., \& Dahlberg, T. (2017). Digital supply chain transformation toward blockchain integration. In proceedings of the 50th Hawaii international conference on system sciences.

[38] Sony, M., \& Naik, S. (2019). Ten Lessons for managers while implementing Industry 4.0. IEEE Engineering Management Review, 47(2), 45-52.

[39] Douaioui, K., Fri, M., \& Mabroukki, C. (2018). The interaction between industry 4.0 and smart logistics: concepts and perspectives. In 2018 International Colloquium on Logistics and Supply Chain Management (LOGISTIQUA) (pp. 128-132). IEEE. 
[40] Sanders, N. R., Boone, T., Ganeshan, R., \& Wood, J. D. (2019). Sustainable supply chains in the age of AI and digitization: research challenges and opportunities. Journal of Business Logistics, 40(3), 229240 .

[41] Vendrell-Herrero, F., Bustinza, O. F., Parry, G., \& Georgantzis, N. (2017). Servitization, digitization and supply chain interdependency. Industrial Marketing Management, 60, 69-81.

[42] Hoffman, D. L., \& Novak, T. (2015). Emergent experience and the connected consumer in the smart home assemblage and the internet of things. Available at SSRN 2648786.

[43] Hsu, C.-L., \& Lin, J. C.-C. (2016). An empirical examination of consumer adoption of Internet of Things services: Network externalities and concern for information privacy perspectives. Computers in Human Behavior, 62, 516-527.

[44] Mani, Z., \& Chouk, I. (2017). Drivers of consumers' resistance to smart products. Journal of Marketing Management, 33(1-2), 76-97.

[45] Frey, C. B., \& Osborne, M. A. (2017). The future of employment: how susceptible are jobs to computerisation? Technological forecasting and social change, 114, 254-280.

[46] Benešová, A., \& Tupa, J. (2017). Requirements for Education and Qualification of People in Industry 4.0. Procedia Manufacturing, 11, 2195-2202.

[47] Ras, E., Wild, F., Stahl, C., \& Baudet, A. (2017). Bridging the skills gap of workers in industry 4.0 by human performance augmentation tools: challenges and roadmap. In Proceedings of the 10th International Conference on PErvasive Technologies Related to Assistive Environments (pp. 428-432). ACM.

[48] de Sousa Jabbour, A. B. L., Jabbour, C. J. C., Foropon, C., \& Godinho Filho, M. (2018). When titans meet-Can industry 4.0 revolutionise the environmentally-sustainable manufacturing wave? The role of critical success factors. Technological Forecasting and Social Change, 132, 18-25.

[49] Bicaku, A., Maksuti, S., Palkovits-Rauter, S., Tauber, M., Matischek, R., Schmittner, C., ... Delsing, J. (2017). Towards trustworthy end-to-end communication in industry 4.0. In Industrial Informatics (INDIN), 2017 IEEE 15th International Conference on (pp. 889-896). IEEE.

[50] Cheng, G.-J., Liu, L.-T., Qiang, X.-J., \& Liu, Y. (2016). Industry 4.0 development and application of intelligent manufacturing. In Information System and Artificial Intelligence (ISAI), 2016 International Conference on (pp. 407-410). IEEE.

[51] Sony, M., \& Naik, S. (2020). Industry 4.0 integration with socio-technical systems theory: A systematic review and proposed theoretical model. Technology in Society, 61(5), 101248.

[52] Singh, S. K., Gupta, S., Busso, D., \& Kamboj, S. (2019). Top management knowledge value, knowledge sharing practices, open innovation and organizational performance. Journal of Business Research. 1-11.

[53] Oberer, B., \& Erkollar, A. (2018). Leadership 4.0: Digital Leaders in the Age of Industry 4.0. International Journal of Organizational Leadership.O Available at SSRN: https://ssrn.com/abstract=3337644.

[54] Guzmán, V. E., Muschard, B., Gerolamo, M., Kohl, H., \& Rozenfeld, H. (2020). Characteristics and Skills of Leadership in the Context of Industry 4.0. Procedia Manufacturing, 43, 543-550.

[55] Aithal, P. S., Shailashree, V., \& Kumar, P. M. (2015). A new ABCD technique to analyze business models \& concepts. International Journal of Management, IT and Engineering, 5(4), 409-423.

[56] Aithal, P. S., \& Kumar, P. M. (2016). CCE Approach through ABCD Analysis of 'Theory A'on 
Organizational Performance. International Journal of Current Research and Modern Education (IJCRME), 1(2), 169-185.

[57] Aithal, P. S., Shailashree, V., \& Kumar, P. M. (2015). Application of ABCD Analysis Model for Black Ocean Strategy. International Journal of Applied Research, 1(10), 331-337.

[58] Aithal, P. S., Shailashree, V., \& Kumar, P. M. (2016). ABCD analysis of Stage Model in Higher Education. International Journal of Management, IT and Engineering, 6(1), 11-24.

[59] Aithal, P. S. (2017). ABCD Analysis as Research Methodology in Company Case Studies. International Journal of Management, Technology, and Social Sciences, 2(2), 40-54.

[60] Sony, M.\&Aithal, P. S. (2020). Transforming Indian Engineering Industries through Industry 4.0: An Integrative Conceptual Analysis.International Journal of AppliedEngineering and Management Letters, 4(2), 111-123.

[61] Sony, M.\&Aithal, P. S. (2020). Practical Lessons for Engineers to adapt towards Industry 4.0 in Indian Engineering Industries. International Journal of Case Studies in Business, IT, and Education, 4(2),86-97.

$* * * * * * * * * * * * * * *$ 